\title{
EL DIETARI DE PERE GIMFERRER: LOS LÍMITES DE LA ESCRITURA
}

\author{
Anna ESTEVE GUILLÉN \\ Universitat d'Alacant \\ anna.esteve@ua.es
}

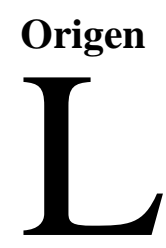

'any 1979, Llorenç Gomis em va proposar d'escriure una cosa cada dia. Vaig començar a fer-ho i em va sortir una cosa molt peculiar» (BIGORDÀ - MARTí: 1990) ${ }^{1}$. Con estas palabras Gimferrer explica el origen de una de las obras más singulares del dietarismo contemporáneo. El entonces director de El Correo Catalán le invitó a publicar una sección diaria escrita en catalán que llevara por título «Correu català» i que fuera a la vez literatura y periodismo; las conversaciones posteriores con el poeta modificaron el título de la sección, que pasó a llamarse, significativamente, «Dietari».

Gimferrer entronca así con una importante tradición de escritores catalanes que a lo largo del siglo XX han colaborado en prensa con una columna estable y, posteriormente, la han incorporado a su obra literaria en forma de libro. El «Glossari», de Xènius, el «Calendario sin fecha», de Josep Pla, o el «Fulls de Dietari», de Carles Soldevila, son compendios de artículos que se publicaron en secciones de periódicos y que en ocasiones presentan, según Enric Bou (1993), un carácter de dietario público o externo. Como ya señaló Josep Pla $(1982,236)$, los escritos de prensa de Carles Soldevila «fan un gran servei perquè acosten insensiblement la gent a llegir en català d'una manera còmoda, normal i positiva», una motivación que también encontramos en la obra que analizamos. El propio Gimferrer reconoce que uno de los propósitos que se planteó era poner en contacto la lengua y literaria catalanas con el mayor número posible de realidades culturales, en el contexto de los años setenta. Subyace, pues, una evidente finalidad cívica y también crítica.

Junto a estos referentes, el Dietari participa de otra tradición más sólida, la que tiene el Quadern gris, de Josep Pla, como modelo y referencia del género. Entendemos que no

\footnotetext{
${ }^{1}$ La cursiva es nuestra.
} 
es gratuito ni casual que Gimferrer modifique la propuesta de Llorenç Gomis para bautizar la sección con el nombre de dietario, como tampoco lo es que, estratégicamente situada como colofón a esta obra, presente un texto dedicado a Josep Pla: «Possible imatge de Josep Pla», en el que es el propio Pla quien da nombre a sus textos: «Vostè escriu un dietari» [... ] L'autor del Quadern gris, l'autor del Dietari, de l'únic Dietari amb lletres capitals, m'ha dit que jo, precisament jo, escric un dietari» (1996: 323).

Además de elogiar el dietario más representativo de la literatura catalana -referente simbólico, que propicia una asociación, premeditada, con el universo creador de Pla y, a su vez, con un tipo de dietario literario, alejado de la intimidad y esquivo a las taxonomías más reduccionistas- funciona como una tarjeta de presentación; es una manera de prestigiar su dietario y de introducirlo de lleno en la tradición literaria catalana; aunque una y otra obra en poco se asemejan. Nuestra intensión será explicar, seguidamente, la singular naturaleza del dietario del poeta.

\section{El Dietari: metáfora del yo y realidad literaria}

Para entender la propuesta creativa de Gimferrer en las páginas de este Dietari conviene tener presente la reflexión del profesor Enric Bou (1988: 394) sobre la actitud radical de Gimferrer, por la que considera el reino de la literatura como una realidad y, a la inversa, la realidad como una forma de retorno a la literatura. Esta es, sin duda, la operación que se trasluce en la obra.

La realidad que muestra como propia en el Dietari huye de la cotidianidad para adentrarse en el magma intenso de la literatura y del arte. Carbonell (1981) habla de la «metàfora de la metàfora, on la realitat esdevé creació de la imaginació. Els ressons del real arriben totalment filtrats, convertits en pura emoció sense referent.» Y no solamente el mundo que muestra esta tamizado por la cultura sino que la estrategia narrativa con la que nos lo hace llegar se transfigura, muy a menudo, en ficción. Gimferrer distingue entre el mundo exterior, que rechaza -y por ello suele refugiarse en otras épocas como la Belle époque o la mitificada Venecia- ${ }^{2}$, y el mundo interior del artista, en el que crea una situación ideal. Suple el mundo que le rodea por otra realidad, poética, que funciona con unas leyes propias y cuya característica principal es la ausencia total de límites entre arte y vida, entre ficción y realidad. Se deriva, pues, una concepción de la literatura donde no hay distinción entre una y otra categoría y, en consecuencia, no ha de sorprendernos que los mecanismos de la ficción asomen por más de un texto del dietario ${ }^{3}$. Gimferrer rompe

\footnotetext{
${ }^{2}$ El autor no se siente en absoluto a gusto en este mundo: «Me parece horrible, feísimo. A mí me hubiera gustado vivir en la Venecia del siglo XVIII o en el París de la época de Proust» (San Agustín, 1988).

${ }^{3}$ Grasset (2007) analiza con detalle las estrategias ficcionales presentes en el Dietari, que contribuyen a abolir las diferencias entre ficción y no ficción, ya que, según el estudioso, cualquier discurso «obeeix a convencions igualment arbitràries i sense cap junció amb la veritat».
} 
así con el estatus de la literatura autobiográfica que, según Genette (1999), es condicionalmente literaria, pero no constitutivamente ${ }^{4}$. Su planteamiento armoniza con las teorías deconstruccionistas, por las que la autobiografía no puede ser otra cosa que ficción, en tanto que el yo que aparece es creación del lenguaje y no puede transcender su naturaleza textual.

Para el autor, la realidad no es más que una metáfora de nuestra experiencia de esta realidad; una experiencia que en Gimferrer se produce mediante el arte, concretamente la literatura y el cine: «la vocació cineclubística i l'assistència a la Filmoteca van formar una part fonamental del que jo sóc» ${ }^{5}$. Así, la realidad que impera en este Dietari aúna y coloca en el mismo nivel discursivo acciones que proceden de mundos con estatus diferentes pero que se confunden en esta obra. Así lo vemos en la prosa datada el 2 de mayo de 1980. Primero, busca la complicidad del lector:

Podem agafar una mitja de seda. La tenim, potser, desada al fons d'un calaix, a la gran calaixera panxuda de caoba o de cedre [...] Des puntes, amb la mitja a la butxaca, sortim al carrer. No ens ha vist ningú [...] Aquest home [...] ¿som nosaltres, sóc jo? (Gimferrer, 1996: 11)

Seguidamente, focaliza el objeto clave del texto: las manos, que no son las de un estrangulador vulgar sino las de todo un dandi «esportiu dinàmic, amb jaqueta de moda». De repente, las manos fuertes del estrangulador pasan a ser otras manos, en una suerte de fundido encadenado: «veiem a contrallum, la punta de les ungles, agudes i retallades. És una mà rabassuda; al darrera hi ha un home calb, grassonet, amb uns ulls petits, irònics i vius». Para confirmar al final del texto -y provocar así un efecto de suspenso o sorpresalas manos de Alfred Hichcock. Referente histórico real, autor y personaje de ficción transitan por una misma realidad, sin distinción.

Desde este punto de vista, cabe afirmar que el Dietari se constituye como una constante metacreación, una escritura de doble fondo, profundamente intertextual, que nos traslada a otras realidades a partir de versos, fotogramas o diálogos. Es capaz de evocar, amplificando y recreando, aventuras de piratas, misterios de Hércules Poirot o del

\footnotetext{
${ }^{4}$ Genette (1991) distinguía entre lo que denominaba obras que eran literarias de manera constitutiva (por ficción o por dicción, es decir, por uso de fantasía e imaginación, o por elaboración de la forma) y obras que eran literarias de manera condicional; o sea, que el lector, en ciertas épocas, decide considerarlas literarias, aunque su intención primera sea otra: moral, histórica, científica... Estas obras, en consecuencia, estaban por definición fuera del camp de la ficción.

${ }^{5} \mathrm{La}$ etapa de formación de Gimferrer determina la posterior imbricación del mundo cinematográfico en su literatura. Él los define como mundos paralelos (Pelfort, 1989), ya que la referencia a películas, personajes cinematográficos, actores... es característica tanto de la poesía como del Dietari, sin mencionar los ensayos críticos o estudios como Cine y literatura (1985), en el que explicita su profundo interés por las relaciones entre los dos artes.
} 
comisario Maigret; lecturas de su infancia y adolescencia. Personajes que, junto al yo protagonista, conviven como ciudadanos del mundo que presenta esta obra ${ }^{6}$.

En esta realidad literaria, sin fronteras, habita un yo que, como hemos apuntado, se construye en el texto literario: «L'autor dels textos no sóc en cap cas jo, cada llengua, cada modalitat literària generen un autor independent de tu que té la seva pròpia vida» (Guillamon, 1985: 5). No se trata de la distancia que cualquier tipo de escritura implica, también la autobiográfica ${ }^{7}$, sino que se trata de una creación acorde con el universo poético que presenta. De entrada, pues, parece que queda suspendida la triple identidad que proclama el pacto autobiográfico acuñado por Philippe Lejeune (1975), y que regula también la escritura y la lectura de dietarios.

Asistimos a la construcción de un personaje a través del cual ofrece la imagen de sí mismo que ha ido edificando a lo largo de su trayectoria pública: obsesiones, fobias, opiniones y preferencias del escritor ${ }^{8}$. No hallaremos, por lo tanto, verdad biográfica o rastros de alguna forma de intimidad referida al individuo; Gimferrer nos ofrece literatura, creación artística, porque: «és en l'art de l'home que hi ha la seua veritat» (1995: 54), ya que la literatura es el espejo donde la consciencia se ve a sí misma. Para el autor, la creación literaria implica una proyección moral de la persona, una exigencia: «disparar contra un mateix», y una autoexploración para poder expresarse y esbozar una imagen nítida de su mundo interior. Esta es la concepción de la literatura que va desgranando a lo largo del dietario, como veremos más adelante.

Si el yo del escritor del Dietari es creación del lenguaje, prosopopeya en expresión de Paul de Man, no ha de extrañar que se manifieste mediante otros yo que pueblan el mundo que nos ofrece en esta obra. Son principalmente artistas que intentan expresar su identidad a través de la propia obra: Van Gogh, Pessoa, Lautréamont...

Estas figuras históricas - procedentes del mundo literario, cinematográfico, pictórico, intelectual...- actúan como metáforas del ideario del escritor, reflejos de la imagen que va erigiendo texto a texto. Los presenta como modelos para mostrar, de manera indirecta, su poética personal y, quizás, también vital. Unos y otros comparten una intención: aspiran a una vida personal auténtica ${ }^{9}$, a ser coherentes con la propia consciencia; Goya o Tolstoi serian algunos de los ejemplos. Así mismo, todos saben ver

\footnotetext{
${ }^{6}$ Así observamos a Bianchon y Rastignac en la calle Faubourg Saint-Honoré de una obra de Balzac (1996: 34), Teresa Valldaura y Eulàlia Berguedà en Mirall trencat (1996: 106) o Ana Ozores viendo el Don Juan de Zorrilla en la Regenta (1996: 248).

${ }^{7}$ Para la estudiosa Anna Caballé (1987: 106-107) «desde el momento en que un yo decide representarse no es más yo, sino alguien diferente de sí mismo [...] puesto que toda representación implica siempre un desvío y una diferencia o, si se quiere, una manipulación».

${ }^{8}$ Un personaje que ha sido descrito por la pluma de escritores y críticos tan reconocidos como Josep Maria Castellet o Andrés Trapiello. El perfil que consigue filmar el crítico catalán en Els escenaris de la memòria es realmente sugerente.

${ }^{9}$ Gimferrer retrata el artista que se niega a representar el papel que le impone la dinámica social (Guillamon, 2001).
} 
la realidad y llegar al fondo del ser humano, a través de la obra creativa, por ello muchos se convierten, por medio de la metonimia, en ojos. Se detiene, así, en los de M. Clift, porque en ellos encuentra los secretos de la consciencia; o enfoca el ojo de Fritz Lang al Hotel Windsor (1996: 94), porque sabe ir en busca de la otra parte del espejo para despertar la consciencia. Otros incluso son ojo físico y moral: Saint-Simon, Proust, Pla o las hermanas Brönte. En especial, destacan los poetas, visionarios, porque saben captar el fondo de la existencia: Mallarmé, Dickinson, Stevens, Aleixandre, además de Baudelaire, Riba, March o Foix. En definitiva, los personajes que comparten protagonismo en el Dietari le sirven para demostrar que vida y obra a menudo se explican, se influyen o se confunden. Es desde esta perspectiva que podemos hablar del dietario como espejo ${ }^{10}$ del escritor.

\section{Pere Gimferrer a través del espejo}

La estrategia ficcional que respira el Dietari lo arroja a los márgenes de la escritura autobiográfica, entendida como literatura de no ficción, como ya hemos mencionado. Sin embargo, desde el punto de vista temático, presenta una variedad que no desentona en absoluto dentro de la tradición dietarística catalana de finales del siglo XX y principios del XXI; responde a lo que hemos cualificado en otras ocasiones de dietario literario o de escritor (Esteve, 2010). Se perfilan, por así decirlo, un dietario cívico o de pensamiento, un dietario de creación, de probatura narrativa; y un dietario, según el autor, en sentido estricto, que responden, en parte, a los diversos intereses y objetivos que se plantea en esta obra.

\section{$\underline{\text { Dietario de la memoria }}$}

En aquellos textos en los que plasma recuerdos y experiencias personales se insinúa cierta geografía personal, aunque parcial, compuesta por una sucesión de instantes, de fotogramas de su vida. Son algunos de los topoi que se suelen reconocer en las autobiografías y en algunos dietarios. Encontramos episodios del colegio y recuerdos de la infancia, vivencias del adolescente, el descubrimiento de la vocación literaria, algún comentario sobre sus profesores de la facultad o las primeras amistades literarias. También anécdotas sobre el servicio militar y el descubrimiento del amor, de la mano de la pianista María Rosa Caminals. Una educación sentimental e intelectual que, para la generación del setenta, transcurre bajo el plomizo telón de fondo del franquismo.

El autor substituye el retrato personal por una presentación del origen del escritor. Nos explica la génesis a través del cine y la literatura, artes que funcionan de filtro para

\footnotetext{
${ }^{10}$ Por este motivo, el recurso del espejo y la máscara, central en toda la creación gimferreriana está lleno de significado. Resulta vía de conocimiento, de autoanálisis, y no solamente como elemento formal.
} 
entender el mundo, durante la adolescencia, y se convierten en el medio para expresar el suyo propio, más tarde.

\section{Dietario del pensamiento}

Desde la sección del «Dietari», Gimferrer define su modelo de intelectual -que asocia directamente al de escritor- como aquella persona más lúcida que tiene el papel de ejercer la crítica independiente. Las figuras a través de las que se expresa (Moratín, Shakarov, Larra y, muy especialmente, J. V. Foix) conforman un modelo de intelectual cuyo compromiso se manifiesta en el silencio, en el rechazo, en el aislamiento. Su función es, según el poeta, perseverar en su cometido, ya sea en el laboratorio, en la biblioteca, en el despacho: traduciendo, creando, experimentando o descubriendo. Al margen del poder que los pueda manipular, corromper o condicionar ${ }^{11}$.

Situado en la tribuna que le ofrece Gomis, el poeta expone su juicio sobre realidades muy diversas: desde la función que debería cumplir la televisión, hasta el mal gusto cinematográfico $^{12}$, pasando por la falta de criterio de los encargados de montar exposiciones. Por encima de estas preocupaciones se impone un compromiso, más fuerte en el escritor, y es el que mantiene con la literatura -intentar escribir bien y ser crítico-, y con la lengua y la cultura. Su reflexión gira en torno a tres grandes temáticas: el Hombre, Catalunya y la Historia.

\section{Dietario de creación}

Prácticamente toda la obra de Gimferrer se interroga sobre la literatura y sus procedimientos creativos; el Dietari, en este sentido, no es una excepción. Según Enric Bou, la prosa literaria ha supuesto una prolongación pero también una ruptura respecto la obra poética del escritor. Las obsesiones persisten pero se formulan en términos narrativos, los cuales permite entender intenciones, procedimientos y concepciones que permanecían expresamente ocultos en la poesía.

Así pues, la poética del instante prima en la poesía, pero es también premisa de la prosa de este dietario privilegiar instantes que se yuxtaponen y se acumulan, momentos que inmortaliza la escritura: la visión de una película, la lectura de un libro... El instante es su piedra roseta, motor de creación y criterio artístico ${ }^{13}$. Con ellos se escapa de este mundo, se abstrae y crea otro ideal; una realidad donde se neutraliza el tiempo del recuerdo (ideal) con el tiempo del instante vivido, con independencia de la fecha que

\footnotetext{
${ }^{11}$ Un buen ejemplo de este modelo de intelectual lo leemos en «Del Nobel Milosz» (1996: 229).

12 Añora, por ejemplo, maravillas perdidas como las películas en 3-D y, con ellas, la posibilidad de un cine diferente. Por este motivo reivindica un espacio alternativo (el cine Aspi en Barcelona) que pueda superar el mal gusto cinematográfico, que según él es el reflejo de la «difuminació general del saber i de la sensibilitat» (1996: 238).

${ }^{13}$ Lo podemos comprobar en una prosa que dedica a Fred Astaire y Gene Kelly (1996: 274), en la que cifra la grandeza del artista en función de la capacidad de construir, con el baile, un instante transitorio.
} 
encabeza cada texto: la simultaneidad histórica de la que habla Castellet (Gimferrer, 1996).

Gimferrer fusiona palabras, movimientos, colores y a partir de la poética del instante funde todas las artes: literatura, pintura, cine. El instante es la unidad básica que las liga: «La pintura és un art de l'instant; el poema és un art de l'instant [...] Mots, colors: llum quieta del que viu a la consciencia» (1996: 147). Esta poética explicita una concepción total del arte, sin fisuras ni fronteras, como un devenir continuo que está en la base del universo que Gimferrer concibe en su obra, la realidad personal y poética que nos propone.

\section{Algunas conclusiones}

En resumen, la singularidad del Dietari se manifiesta en un género que sirve al autor como punto de partida para continuar profundizando en el recurso del espejo presente en buena parte de su obra. Si bien comparte elementos con los dietarios más tradicionales que justifican su filiación, no deja de situarse en el límite. Gimferrer parece querer experimentar con la base del dietario para dinamitarlo por dentro y crear una nueva versión. Percibimos el perfil, la silueta, del dietario pero el concepto y la intención lo trascienden.

En esta obra se plasma la distancia insalvable que hay entre el yo real y el yo de la escritura que se convierte en creación del lenguaje. En su lugar aparece el personaje que se expresa a través del espejo (de los otros), para mostrar y demostrar que en Gimferrer vida y obra se suplantan; una fusión que, a su vez, se proyecta en una realidad literaria que nace del mundo interior del escritor, compuesto de lecturas y celuloide.

Libertad absoluta y escritura al límite, por lo tanto, son la esencia que transpira esta obra. Alterna textos que encajan con la publicación periodística con auténticos micro relatos independientes que narran historias nacidas del imaginario del poeta. La intención última, con todo, es hacer arte a partir del arte (pintura, literatura, cine, música) y de las experiencias propias (recordadas) o de las de otros personajes que habitan en su universo: las recrea, las imagina, las dibuja, las filma. En el fondo, estas modulaciones formales responden a la rica y compleja relación que establece entre la ficción y la no-ficción. Alojado en la frontera, el Dietari la transgrede casi en cada texto; referentes no ficcionales y elementos de ficción se confunden, sin límites, se entrelazan dos mundos y se explican el uno al otro.

El dietario es, en conclusión, una obra de experimentación en la que Gimferrer aprovecha la invitación de Llorenç Gomis para ejercer de intelectual y generar opinión sobre aspectos culturales y políticos de la sociedad catalana de aquellos años; para ensayar unas técnicas narrativas que más tarde culminarán en la novela Fortuny. Una obra libre y 
compleja que deshace cualquier restricción, de escritura y de género, se alimenta de cultura y se escribe en imágenes.

\section{Bibliografía}

BigordÀ, J. - MARTí GÓMEZ, J. (1990): «Pere Gimferrer», Barcelona: metròpolis mediterrània, 16, pp. 129-133.

Bou, E. (1988): «Pere Gimferrer», en DE RIQUER, M. -COMAS, A. -MolAS, J., en Història de la literatura catalana. vol. XI, Barcelona, Ariel, pp. 385-394.

_ (1993): Papers privats. Assaig sobre les formes literàries autobiogràfiques. Barcelona, Ed. 62.

CABAlLÉ, A. (1987): «Figuras de la autobiografía», Revista de Occidente, 74-75, pp. 103119.

CARbonell, M. (1981): «Imatges en un mirall: el Dietari de Pere Gimferrer», Els Marges, 22-23, pp. 130-132.

CAstellet, J. M. (1988): «Pere Gimferrer», en Els escenaris de la memòria. Barcelona, Ed. 62, pp. 249-262.

- (1996): «Introducció», en GIMFERRER, P., Dietari Complet, 3. Obra Catalana Completa/3. Barcelona, Ed. 62, pp. 5-16.

EsTeVE, A. (2012): El dietarisme català entre dos segles (1970-2000). BarcelonaAlacant, PAM-IIFV.

GenetTe, G. (1991): Ficción y dicción. Barcelona, Lumen, 1993. (1999): «Du texte à l'œuvre», en Figues IV. París, Editions du Seuil, pp. 7-45.

GiMfERrer, P. (1995): Dietari Complet, 2. Obra Catalana Completa/2. Barcelona, Ed. 62.

(1996): Dietari Complet, 3. Obra Catalana Completa/3. Barcelona, Ed. 62.

GRASSET, E. (2007): «"Dietari ver, dietari fals, dietari” El Dietari de Pere Gimferrer, un moviment cap a la ficció», en BORJA, J. et ali (ed.)., Diaris i dietaris. AlacantValència, Denes, pp. 457-466.

Guillamon, J. (1985): «Pere Gimferrer, més enllà dels miralls», Avui del diumenge (27/1/85), pp. 5-6.

- (2001): La ciutat interrompuda. Barcelona, La Magrana.

LeJEune, P. (1975): Le pacte autobiographique. París, Éditions du Seuil.

PlA, J. (1982): Retrats de passaport, Obra completa 17. Barcelona, Destino.

PELFORT, J. (1989): «El cinema al Dietari (1979-1980 i 1980-1982). Aproximació a l'estudi de les relacions cinema-literatura a l'obra de Pere Gimferrer», Els Marges, 39, pp. 109-119. 
148 Tropelías. Revista de Teoría de la Literatura y Literatura Comparada, 20 (2013) Anna Esteve Guillén

SAn Agustín, A. (1988): «Vals con paraguas», El periódico. El Dominical (14/II/1988), pp. 4-7. 